\title{
Comparing Molecular Biomarker Testing With Immunohistochemical Staining In Predicting Response To Neoadjuvant Therapy In Breast Cancer
}

Mahmoud Abdel-Ghany Behairy ( $\sim$ Mahmoud.behairy@kasralainy.edu.eg )

Cairo University

\section{Samia Mohmed Gabal}

Cairo University

Wafaa Hasan El Metenawy

Cairo University

Loay Mohamed Kasem

Cairo University

Lubna omar Abel-Salam

Cairo University

Research Article

Keywords: Breast cancer , IHC , STRAT4

Posted Date: March 2nd, 2022

DOI: https://doi.org/10.21203/rs.3.rs-1399752/v1

License: (c) (i) This work is licensed under a Creative Commons Attribution 4.0 International License.

Read Full License 


\section{Abstract}

Background: Breast cancer $(\mathrm{BC})$ is the most common cancer type among women world-wide and the major cause of cancer deaths. Many factors affect the prognosis and treatment of BC such as histological grading, staging, as well as the biological markers: Estrogen receptor (ER), Progesterone receptor (PR), HER2 and Ki67. Immunohistochemistry (IHC) remains the corner stone in determining ER, PR, HER2 and Ki67 status for breast cancers, however limitations still exist concerning analytic validity \& interpretation. mRNA expression assays can provide an alternative innovative method for measuring these biomarkers. The Xpert Breast Cancer STRAT4 Assay is an in vitro diagnostic test for the determination of overexpression or non-overexpression of ER, PR, HER2 and Ki67 mRNA isolated from $10 \%$ neutral buffered FFPE invasive breast tissue.

Objectives: Comparing results (concordance) of IHC of ER, PR, Ki67 and Her2 with mRNA gene expression analysis results by STRAT4 for each of the biomarkers tested on the same sample blocks \& correlating the results of $\mathrm{IHC}$ with the clinico-pathologic parameters of the tumours and clinical outcome of patients.

Materials and methods: One hundred BC tissue sections were collected from needle biopsies specimens \& were evaluated for expression of the four biomarkers (ER, PR, KI67, Her-2) using IHC and the same blocks were sectioned and tested for mRNA gene expression by the Xpert breast cancer STRAT4 for the same markers.

Results: Concordance rate between mRNA expression and IHC was $96 \%$ for ER, $94.7 \%$ for PR, $93 \%$ for HER-2, 97.9\% for Ki67, with Kappa measurement showing strong to perfect agreement in the 4 parameters (all > 80\%).

Conclusion: The study reveals high concordance between central IHC and mRNA measurements of the four main breast cancer biomarkers. STRAT4 can provide an effective modality for standardized results for breast cancer patients.

\section{Introduction}

In the era of precision medicine, cancer management becomes dependent on the biological and genetic alterations discovered in several malignancies. On top of theses malignancies is breast cancer. Breast cancer is currently the most common women malignancy and is the first cause of cancer deaths in women ${ }^{[1]}$.

At present, the prognosis, classification and treatment of $\mathrm{BC}$ are dependent not only on tumor histological grading and stage, but also on other major protein markers as Estrogen receptor (ER), Progesterone receptor (PR), HER2 and proliferation marker Ki67 ${ }^{[2]}$.

ER and PR are mainly useful in determining the need for endocrine therapy for some BC patients ${ }^{[3]}$. The probability of response to this endocrine therapy is dependent on the level of hormone receptors which is 
associated with much less benefit of chemotherapy ${ }^{[4]}$.

ERBB2 (HER2) gene amplification paved the way for development of HER2-targeted therapies. The Proliferation marker Ki-67 (MKi67) is very important in several types of cancer. In early breast cancer, the worse survival outcomes have been associated with the higher Ki67 level ${ }^{[5]}$.

Evaluation of Estrogen receptor, Progesterone receptor, HER2 expression and Ki76 index with the use of immunohistochemistry (IHC) is the classical method of assessment for gene based targeted therapies of breast cancer ${ }^{[6]}$.

These methods although are at reach and classically used in all pathology labs. Yet with IHC, subjective variability may exist due to issues such as differences in tissue fixation, antibody used \& methods of interpretation which may lead to false negative/positive results, especially for HER2 \& Ki67 proteins ${ }^{\text {[7] }}$.

Assays for mRNA expression provide an alternative approach for measuring these biomarkers. A RTqPCR-based diagnostic platform called the GeneXpert ${ }^{\circledR}$, (Cepheid, Sunnyvale, CA, USA), which is incorporated in a device referred to as Xpert ${ }^{\circledR}$ Breast Cancer STRAT4, was developed to detect mRNA expression of ER, PR, HER-2 \& Ki67 from formalin-fixed, paraffin-embedded (FFPE) tumor tissue ${ }^{\text {[8] }}$.

Stimulated by this, we aimed to explore the value of breast cancer biomarker analyses using RT-qPCR based assay for mRNA expression in comparison with standard IHC performed at central laboratory for the same biomarkers and correlate this with the pathological response to neoadjuvant systemic therapy received.

\section{Material \& Methods}

\section{Retrieval of Cases}

The material of this prospective study was collected from formalin fixed, paraffin embedded tumor tissue sections of core needle biopsy specimens of 100 breast patients with radiological and pathological evidence of breast cancer. The cases were collected from the Pathology Department, Kasr El Aini Hospital, Cairo University, Egypt in the time period between March 2019 and March 2020. The authors obtained the approval of ethical committee in the faculty of Medicine, Cairo University.

The MDT (multi-disciplinary team) of breast cancer referred the patients for neoadjuvant therapy and they were followed up till the regimen of the therapy was completed and surgical excisions were done. The histopathological evaluation was done for the postoperative excision biopsies for assessment of the response to neoadjuvant therapy.

\section{Histopathological \& Immunohistochemical Examination}

The paraffin blocks of the tumor tissue were serially sectioned at $4 \mu \mathrm{m}$ thickness, stained with routine Hematoxylin \& Eosin stains for pathological examination according to the WHO recommendations ${ }^{[9]}$. 
All cases were referred to Tumor marker unit, Pathology department, Kasr al ainy for evaluation of the ER, PR, HER2 and Ki67. All the specimens were assessed immunohistochemically for detection of the four biomarkers using Ventana PenchMark XT. The used antibodies were primary monoclonal antibodies including anti-(ER) (SP1) Rabbit, anti-(PR) (1E2) Rabbit, anti-HER-2/neu (4B5) Rabbit and anti-Ki-67 (30 9) Rabbit. UltraView Universal DAB is the Detection Kit used.

ER/PR interpretation was done according to the Allred scoring system ${ }^{[10]}$. HER-2 interpretation was done according to the ASCO/CAP guidelines $2018^{[11]}$. While for Ki67, we used the cut-off point between 'high' and 'low' values $\geq 20 \%$ being the new cut-off approved in 2013 by St Gallen conference ${ }^{[12]}$.

\section{Molecular Biomarker testing:}

All the specimens were subjected to automated Real-time Polymerase Chain Reaction (RT-qPCR) for assessment of RNA expression for ER, PR, HER2, and Ki67 using the Xpert $\circledast$ Breast Cancer STRAT4 \& its diagnostic platform, the GeneXpert®, [(Cepheid, Sunnyvale, CA, USA)].

The GeneXpert is an automated system integrating sample purification, nucleic acid amplification, and target sequence detection in simple or complex samples. The system consist of an instrument, barcode scanner, computer, and pre-loaded software for running tests and viewing the results. The system requires the use of single-use, disposable GeneXpert cartridges that hold the RT-PCR reagents and host the RT-PCR process.

The steps of the process were followed according to the package instructions. The FFPE tissue was first macrodissected and scraped from the tumor rich area after examining the H\&E section then placed into a $1.5 \mathrm{~mL}$ tube, to be admixed with $1.2 \mathrm{~mL}$ of FFPE lysis reagent and $20 \mu \mathrm{L}$ of proteinase $\mathrm{K}$. Then the samples were incubated at $80^{\circ} \mathrm{C}$ for $30 \mathrm{~min}$. After that $1.2 \mathrm{ml}$ of ethanol was added. Finally, The sample lysate (about $520 \mu \mathrm{L}$ ) was shifted to the STRAT4 cartridge and placed into a GeneXpert module for RNA extraction, purification, and RT-qPCR analysis.

All reagents required for sample preparation and RT-PCR analysis are preloaded in the cartridge. Nucleic acids in the lysate are captured on a filter, washed, and eluted by sonication. The purified nucleic acid is mixed with dry RT-PCR reagents, and the solution is transferred to the reaction tube for RT-PCR and detection. Time to result is approximately 75 minutes in the GeneXpert.

\section{Results}

This study included 100 cases of breast carcinoma. The age of them ranged from 25 to 88 years with a mean of $47 \pm 11.31$ years. Among the studied cases, $81 \%$ of were invasive mammary carcinoma (NST) while $14 \%$ were invasive lobular carcinoma and only $5 \%$ were other special types. Concerning grade, $71 \%$ of the cases were grade II \& $29 \%$ were grade III. Regarding cT stage, $11 \%$ were T1, $69 \%$ were classified as $\mathrm{T} 2,14 \%$ were $\mathrm{T} 3$, and $6 \%$ were $\mathrm{T} 4$. 


\section{Concordance between IHC and Molecular Testing of mRNA of the Four Breast Biomarkers}

ER: Among the 100 studied cases, expression of ER protein by IHC was 55 positive cases $\& 45$ negative cases. While by ER mRNA was 51 positive cases and 49 negative cases with an overall concordance rate of the STRAT4 ER results compared with IHC results, $96 \%$. The Kappa measure of agreement showed perfect agreement $(\mathrm{K}=0.92,95 \% \mathrm{Cl}, \mathrm{P}<0.0005)$. The sensitivity (positive percent agreement) was $92.7 \%$ while the specificity (Negative percent agreement) was $100 \%$.

PR: expression of PR protein by IHC was 61 positive cases \& 39 negative cases. While by PR mRNA was 60 positive cases , 35 negative cases and 5 indeterminate cases (excluded from the results). The overall concordance rate of the STRAT4 PR results compared with IHC results (excluding the indeterminate cases) was $94.7 \%$. The Kappa measure of agreement showed perfect agreement $(\mathrm{K}=0.88,95 \% \mathrm{Cl}, \mathrm{P}<$ 0.0005). The sensitivity (positive percent agreement) was $96.6 \%$ while the specificity (Negative percent agreement) was $91.7 \%$

HER2: expression of HER2 protein by IHC was 27 positive cases \& 73 negative cases. While by HER2 mRNA was 24 positive cases and 76 negative cases, with an overall concordance rate between the STRAT4 HER2 results compared with IHC results $93 \%$. The Kappa measure of agreement showed perfect agreement $(\mathrm{K}=0.81,95 \% \mathrm{Cl}, \mathrm{P}<0.0005)$. The sensitivity (positive percent agreement) was $81.5 \%$ while the specificity (Negative percent agreement) was $97.3 \%$

Ki67: expression of Ki67 protein by IHC was 84 cases with high proliferation (considered positive) \& 16 cases with low proliferation (considered negative). While by Ki67 mRNA was 81 positive cases , 14 negative cases and 5 indeterminate (excluded from the results). The overall concordance rate between the STRAT4 Ki67 results compared with IHC results (excluding the indeterminate cases) was $97.8 \%$. The Kappa measure of agreement showed perfect agreement $(\mathrm{K}=0.91,95 \% \mathrm{Cl}, \mathrm{P}<0.0005)$. The sensitivity (positive percent agreement) was $98.8 \%$ while the specificity (Negative percent agreement) was $92.9 \%$.

\section{Table (1)}

\section{Comparison between mRNA expression \& IHC of the four biomarkers.}




\begin{tabular}{|lllll|}
\hline & ER & PR & HER2 & Ki67 \\
\hline IHC+ / mRNA+ & 51 & 57 & 22 & 80 \\
\hline IHC+ / mRNA- & 4 & 2 & 5 & 1 \\
\hline IHC- / mRNA+ & 0 & 3 & 2 & 1 \\
\hline IHC- / mRNA- & 45 & 33 & 71 & 13 \\
\hline Total cases & 100 & 95 & 100 & 95 \\
\hline Kappa measure of agreement (K) & 0.92 & 0.88 & 0.81 & 0.91 \\
\hline Positive predictive value & $100 \%$ & $95 \%$ & $91.7 \%$ & $98.8 \%$ \\
\hline Negative predictive value & $91.8 \%$ & $94.3 \%$ & $93.4 \%$ & $92.9 \%$ \\
\hline Sensitivity (PPA) & $92.7 \%$ & $96.6 \%$ & $81.5 \%$ & $98.8 \%$ \\
\hline Specificity (NPA) & $100 \%$ & $91.7 \%$ & $97.3 \%$ & $92.9 \%$ \\
\hline Concordance rate & $96 \%$ & $94.7 \%$ & $93 \%$ & $97.8 \%$ \\
\hline
\end{tabular}

\section{Response To therapy:}

Therapy received was either chemotherapy (NACT) alone (45 cases), NACT together with endocrine therapy (NAHT) (34 cases) or NACT as well as trastuzumab (21 cases).

According to Chevallier Method, Of these 100 studied cases, 28 cases reached a pathological complete response (pCR), 55 cases showed only partial response (pPR), 17 cases showed no response (pNR) [8 cases showed stable or progressive disease and 9 cases were metastatic].

And according to AJCC "y" Classification system, they showed the following ypTNM after neoadjuvant therapy:

For ypT: 28 cases were T0, 30 cases were T1, 26 cases were T2, 6 cases were T3 and one case was T4 For ypN: 42 cases were N0, 19 cases were N1, 21 cases were N2 and 9 cases were N3

For M: 9 cases were metastatic (no surgery done).

The cases were classified into the following anatomic stage groups, stage III (34 cases) followed by Stage II ( 21 cases), Stage IV (9 cases) and finally Stage I ( 8 cases). Those with pCR were excluded from this staging.

The response to therapy was significantly correlated with different neoadjuvant regimens used, ( $p$ value $=0.041)$, where patients who received NACT and Herceptin showed the highest response rate $(95.2 \%$ 
showed response, either pCR or pPR) \& those who received NACT \& NAHT showed the least $(70.6 \%)$. Meanwhile, pCR rate was the same among NACT only group \& NACT+ Herceptin group (33.3\% each) and also the lowest in NACT+ NAHT group (17.6\%).

In correlation with molecular subtypes, HER-2 enriched showed the highest percentage of cases who were down staged (showed response either pCR or pPR) and was about $95 \%$. And the complete response (pCR) was higher among triple negative (44.4\%) and Her2 enriched (47.4\%) types than luminal types $(21.7 \%$ for type A \& $20 \%$ for type B) with statistically significant correlation ( $p$ value $=0.021$ ).

Concerning the correlation of the response with the immunohistochemical profiles of the patients (according to which they received their therapy), ER showed a significant correlation ( $p$ value $=0.040$ ) where, ER negative cases achieved pCR (40\%) more than ER positive cases (18.2\%), and the percentage of cases who showed no response was higher among ER positive patients. No significant correlation was seen in correlation with PR ( $p$ value $=0.371)$. Regarding HER-2, the correlation was significant $(p$ value $=$ $0.031)$ \& we noticed that HER2 positive cases showed response (either pCR or pPR) (96.3\%), more than HER-2 negative cases (78.2\%). while for Ki67, the correlation was statistically non-significant ( $p$ value $=$ $0.308)$.

Tumor grade showed a statistically significant correlation with the response to neoadjuvant therapy, $(P$ value $=0.036)$, where the pathological complete response was higher among grade III tumors $(46.4 \%)$ than grade II (20.8\%). No significant correlation was seen with the different histological types ( $p$ value $=0.164$ ), but we noticed that ILC cases showed more resistance to treatment where, the pNR rate was higher among ILC (35.7\%) than in IDC patients (13.6\%).

Table (2)

Correlation of response to neoadjuvant therapy with various pathological \& immunohistochemical characteristics among the studied cases. 


\begin{tabular}{|c|c|c|c|c|c|}
\hline \multirow[t]{2}{*}{$\begin{array}{l}\text { Pathological \& immunological } \\
\text { characteristics }\end{array}$} & & \multicolumn{2}{|c|}{$\begin{array}{l}\text { Down staging } \\
\text { (response) }\end{array}$} & \multirow{2}{*}{$\begin{array}{l}\text { No } \\
\text { response } \\
\text { (pNR) }\end{array}$} & \multirow[t]{2}{*}{$P$ value } \\
\hline & & PCR & pPR & & \\
\hline \multirow[t]{3}{*}{ Neoadjuvant Therapy recieved } & NACT & $\begin{array}{l}15 \\
{[33.3 \%]}\end{array}$ & $\begin{array}{l}24 \\
{[53.3 \%]}\end{array}$ & $6[13.3 \%]$ & \multirow{3}{*}{$\begin{array}{l}0.041^{*} \\
\text { (response vs. } \\
\text { No response) }\end{array}$} \\
\hline & NACT+NAHT & $\begin{array}{l}6 \\
{[17.6 \%]}\end{array}$ & $\begin{array}{l}18 \\
{[52.9 \%]}\end{array}$ & $\begin{array}{l}10 \\
{[29.4 \%]}\end{array}$ & \\
\hline & NACT+Herceptin & $\begin{array}{l}7 \\
{[33.3 \%]}\end{array}$ & $\begin{array}{l}13 \\
{[61.9 \%]}\end{array}$ & $1[4.8 \%]$ & \\
\hline \multirow[t]{4}{*}{ Molecular subtypes } & Luminal A & $\begin{array}{l}5 \\
{[21.7 \%]}\end{array}$ & $\begin{array}{l}13 \\
{[56.5 \%]}\end{array}$ & 5 [21.7\%] & \multirow{4}{*}{$\begin{array}{l}0.021^{*} \\
\text { (pCR vs. } \\
\text { other } \\
\text { groups) }\end{array}$} \\
\hline & Luminal B & $6[15 \%]$ & $\begin{array}{l}26 \\
{[65 \%]}\end{array}$ & 8 [20\%] & \\
\hline & Triple negative & $\begin{array}{l}8 \\
{[44.4 \%]}\end{array}$ & 7 & 3 [16.7\%] & \\
\hline & HER2 Enriched & $\begin{array}{l}9 \\
{[47.4 \%]}\end{array}$ & $\begin{array}{l}9 \\
{[47.4 \%]}\end{array}$ & $1[5.3 \%]$ & \\
\hline \multirow[t]{2}{*}{ ER } & Positive & $\begin{array}{l}10 \\
{[18.2 \%]}\end{array}$ & $\begin{array}{l}33 \\
{[60 \%]}\end{array}$ & $\begin{array}{l}12 \\
{[21.8 \%]}\end{array}$ & \multirow[t]{2}{*}{$0.040^{*}$} \\
\hline & Negative & $\begin{array}{l}18 \\
{[40 \%]}\end{array}$ & $\begin{array}{l}22 \\
{[48.9 \%]}\end{array}$ & $5[11.1 \%]$ & \\
\hline \multirow[t]{2}{*}{ PR } & Positive & $\begin{array}{l}14 \\
{[23 \%]}\end{array}$ & $\begin{array}{l}36 \\
{[59 \%]}\end{array}$ & 11 [18\%] & \multirow[t]{2}{*}{0.371} \\
\hline & Negative & $\begin{array}{l}14 \\
{[35.9 \%]}\end{array}$ & $\begin{array}{l}19 \\
{[48.7 \%]}\end{array}$ & $6[15.4 \%]$ & \\
\hline \multirow[t]{2}{*}{ HER-2 } & Positive & $\begin{array}{l}9 \\
{[33.3 \%]}\end{array}$ & $\begin{array}{l}17 \\
{[63 \%]}\end{array}$ & $1[3.7 \%]$ & \multirow{2}{*}{$\begin{array}{l}0.031^{*} \\
\text { (response vs. } \\
\text { No response) }\end{array}$} \\
\hline & Negative & $\begin{array}{l}19 \\
{[26 \%]}\end{array}$ & $\begin{array}{l}38 \\
{[52.1 \%]}\end{array}$ & $\begin{array}{l}16 \\
{[21.9 \%]}\end{array}$ & \\
\hline \multirow[t]{2}{*}{ Ki67 } & High & $\begin{array}{l}21 \\
{[25 \%]}\end{array}$ & $\begin{array}{l}48 \\
{[57.1 \%]}\end{array}$ & $\begin{array}{l}15 \\
{[17.9 \%]}\end{array}$ & \multirow[t]{2}{*}{0.308} \\
\hline & Low & 7 & 7 & $2[12.5 \%]$ & \\
\hline \multirow[t]{2}{*}{ Histopathological Grade } & Grade 2 & $\begin{array}{l}15 \\
{[20.8 \%]}\end{array}$ & $\begin{array}{l}44 \\
{[61.1 \%]}\end{array}$ & $\begin{array}{l}13 \\
{[18.1 \%]}\end{array}$ & \multirow[t]{2}{*}{$0.036 *$} \\
\hline & Grade 3 & $\begin{array}{l}13 \\
{[46.4 \%]}\end{array}$ & $\begin{array}{l}11 \\
{[39.3 \%]}\end{array}$ & $4[14.3 \%]$ & \\
\hline Histopathological Type & IDC & $\begin{array}{l}24 \\
{[29.6 \%]}\end{array}$ & $\begin{array}{l}46 \\
{[56.8 \%]}\end{array}$ & $\begin{array}{l}11 \\
{[13.6 \%]}\end{array}$ & 0.164 \\
\hline
\end{tabular}




\begin{tabular}{llll} 
ILC & 4 & 5 & $5[35.7 \%]$ \\
& {$[28.6 \%]$} & {$[35.7 \%]$} & \\
Special Types & $0[0 \%]$ & $4[80 \%]$ & $1[20 \%]$ \\
\hline
\end{tabular}

*Statistically Significant

\section{Discussion}

Hormone receptors, HER2 and Ki67 are considered now as a crucial step in the management and prognosis for breast cancer (BC). mRNA based approach for evaluation of these markers could present a more valuable and accurate method than the current used modality. The Xpert® Breast Cancer STRAT4, is the prototype device for this method. We compared mRNA expression analysis of ER, PR, HER2, and ki67, with central immunohistochemistry $(\mathrm{IHC})$ by recruiting 100 breast cancer patients from Kasr El Ainy Hospitals, Cairo University, Egypt.

In our study, there was a high overall concordance rate between the STRAT4 results compared with IHC results concerning the four biomarkers ( $96 \%$ for ER, $94.7 \%$ for PR, $93 \%$ for HER2 \& $97.8 \%$ for Ki67) \& the Kappa measure of agreement showed perfect agreement ( $K=0.92$ for ER, 0.88 for PR, 0.81 for HER2 \& 0.91 for Ki67). While the sensitivity (positive percent agreement) was $92.7 \%$ for ER, $96.6 \%$ for PR, $81.5 \%$ for HER2 \& 98.8\% for Ki67 and the specificity (Negative percent agreement) was 100\% for ER, $91.7 \%$ for PR, $97.3 \%$ for HER2 \& $92.9 \%$ for Ki67.

Wu et al., $2018^{[8]}$ \& Fillipits et al., $2021^{[13]}$ in their studies to compare the two modalities, show also a high concordance rate of ER \& was close to ours (97.8\% \& 98.9\%) respectively, with also nearly the same Kappa agreement $(91.8 \%)$ in Wu et al., $2018^{[8]}$ study, but a slightly lower results were reported in Denkert et al., $2019^{[14]}$, lower concordance rate (89.7\%), lower Kappa coefficient $(79.38 \%)$.

While concerning PR, most of the studies showed slightly lower results related to comparing IHC \& STRAT4 as seen in Fillipits et al., $2021^{[13]}$, Janeva et al., $2021^{[15]} \&$ Wu et al., $2018^{[8]}$ with concordance rates $(89.9 \%, 89 \% \& 90.4 \%)$ respectively.

For HER2, A close figure to our results was mentioned in Wasserman et al., 2017 [16], with a concordance rate $91.25 \%$, specificity of $94 \%$ \& slightly higher sensitivity (87\%). A higher concordance rate was seen in Fillipits et al., $2021^{[13]}$ \& Mugabe et al., $2021^{[17]}$ (98.2\% \& 97.8\%) respectively. As noticed in ER \& PR, Denkert et al., $2019^{[14]}$ in their study showed also a lower concordance rate for HER2 than ours (81.7\%).

In most of the literature, results concerning the Ki67 were lower than our study as Fillipits et al., $2021^{[13]}$ \& Janeva et al., $2021^{[15]}$ showed concordance rates (84.4\% \& 76\%) respectively, but the same high sensitivity was reported in Denkert et al., $2019^{[14]}(97.8 \%)$, yet the specificity was very low $30.6 \%$.

Several points could offer an explanation for these differences seen between studies and ours. First, some studies used old blocks archived for long periods as in Fillipits et al., $2021^{[13]}$ which used samples 
from 1990 to 1995 which were incorporated in the ABCSG trial 6. Also in Wu et al., $2018^{[8]}$ study, some of the blocks used aged 22 years. This long period can lead to mRNA degradation, but our study was prospective, whereas the patients are chosen then the samples are collected and tested.

Second, the type of biopsy used for testing can offer a further explanation, as some studies used CNB, others used surgical excision specimens and some tested on both types. And this can readily affect the results especially when using surgical excision specimens with extensive DCIS or tissue sections with large amount of adjacent normal breast tissue and other precursor lesions which will affect the results particularly if the tumor is ER/PR negative. This was avoided in our study as we used CNB specimens \& further examining all the samples by standard H\&E pathology sections, determining, locating \& scraping the exact invasive tumor tissue and excluding any normal tissue or non-invasive tumor.

Another possible factor that might account for the higher concordance documented in this study is the amount of tumor tissue in the sample tested, as if the tumor tissue is insufficient, this will render the STRAT4 test indeterminate or negative especially for PR \& Ki67 so we tried harder to choose samples that contain enough invasive tumor tissue and excluding the few indeterminate cases from our analysis.

Furthermore, the usage of different clones for IHC as well as the different cut off values used with Ki67 between different studies, different methods of interpretation \& subjective variability in IHC interpretation can be a key point for figuring out theses variances.

Regarding the post-neoadjuvant systemic therapy response, $28 \%$ reached pCR, $55 \%$ showed only partial response, $8 \%$ showed stable or progressive disease while $9 \%$ was metastatic. Comparing this to Silver et al., $2010^{[18]}$ showed different results, only $17.8 \%$ showed complete response, $50 \%$ showed partial response \& $32.2 \%$ showed either stable or progressive course. This difference can be explained by the small sample in Silver et al., study (only 28 patients). Also Zhao et al., $2015^{[19]}$ \& Olfatbakhsh et al., 2018 ${ }^{[20]}$ showed lower rate of complete response among their study groups, $(14 \% \& 19 \%)$ respectively.

The rates of pathological complete response differed between the molecular subtypes, with $21.7 \%$ for luminal $A, 15 \%$ for luminal B, $47.4 \%$ for HER2/neu-enriched, and $44.4 \%$ for triple-negative subtype. These were near to that reported by Zhao et al., $2015^{[19]}$ in his study.

\section{Conclusion}

This study sheds light on the recently postulated role of mRNA gene expression analysis by STRAT4 as a rapid, effective and accurate modality for assessment \& biological subtyping of breast cancer patients, as it reveal high concordance between results of the four main biomarkers of breast carcinoma using mRNA gene expression analysis by STRAT4 and the central immunohistochemistry.

\section{Declarations}




\section{Conflict of interest:}

The authors declare that they have no conflict of interest.

\section{Funding:}

This research received no funding.

Cepheid, Sunnyvale, CA, USA. only provided the test cartridges for the molecular testing. Yet, it had no role in the conduct of this study; collection, management, analysis and interpretation of the data.

\section{References}

1. Torre LA, Siegel RL, Ward EM and Jemal A (2016). Global Cancer Incidence and Mortality Rates and Trends--An Update. Cancer Epidemiol Biomarkers Prev.;25(1):16-27.

https://cebp.aacrjournals.org/content/25/1/16.short

2. Coates AS, Winer EP, Goldhirsch A, Gelber RD, Gnant M, Piccart-Gebhart M, Thürlimann B and Senn HJ; Panel Members (2015). Tailoring therapies-improving the management of early breast cancer: St Gallen International Expert Consensus on the Primary Therapy of Early Breast Cancer 2015. Ann Oncol.;26(8):1533-1546. https://www.sciencedirect.com/science/article/pii/S-0923753419318502

3. Duffy MJ, Harbeck N, Nap M, Molina R, Nicolini A, Senkus E and Cardoso F7 (2017). Clinical use of biomarkers in breast cancer: Updated guidelines from the European Group on Tumor Markers (EGTM). Eur J Cancer;75:284-

298. https://www.sciencedirect.com/science/article/pii/S0959804917300758

4. Senkus E, Kyriakides S, Ohno S, Penault-Llorca F, Poortmans P, Rutgers E, Zackrisson S and Cardoso F; ESMO Guidelines Committee (2015). Primary breast cancer: ESMO Clinical Practice Guidelines for diagnosis, treatment and follow-up. Ann Oncol.;26 Suppl 5:v8-

30. https://www.annalsofoncology.org-/article/S0923-7534(19)47181-0/fulltext

5. Stuart-Harris, R., Caldas, C., Pinder, S. E., \& Pharoah, P. (2008). Proliferation markers and survival in early breast cancer: a systematic review and meta-analysis of 85 studies in 32,825 patients. The Breast, 17(4), 323-334. https://www.sciencedirect.com/science/article/pii/S0960977608000593

6. Cancello, G., Maisonneuve, P., Rotmensz, N., Viale, G., Mastropasqua, M. G., Pruneri, G., ... \& Colleoni, M. (2010). Prognosis and adjuvant treatment effects in selected breast cancer subtypes of very young women (< 35 years) with operable breast cancer. Annals of oncology, 21(10), 19741981. https://www.sciencedirect.com/science/article/pii/S0923753419395766

7. Roepman, P., Horlings, H. M., Krijgsman, O., Kok, M., Bueno-de-Mesquita, J. M., Bender, R., ... \& van de Vijver, M. J. (2009). Microarray-based determination of estrogen receptor, progesterone receptor, and HER2 receptor status in breast cancer. Clinical Cancer Research, 15(22), 70037011. https://clincancerres.aacrjournals.org/content/15/22/7003.short 
8. Wu, N. C., Wong, W., Ho, K. E., Chu, V. C., Rizo, A., Davenport, S., ... \& Biernat, W. (2018). Comparison of central laboratory assessments of ER, PR, HER2, and Ki67 by IHC/FISH and the corresponding mRNAs (ESR1, PGR, ERBB2, and MKi67) by RT-qPCR on an automated, broadly deployed diagnostic platform. Breast cancer research and treatment, 172(2), 327-

338. https://link.springer.com/article/10.1007/s10549-018-4889-5

9. Lakhani SR, Ellis IO, Schnitt SJ, Tan PH and van de Vijver MJ (eds) (2012). WHO classification of tumors of the breast. 4th edition. IARC: Lyon 2012.

10. Hammond, M. E., Hayes, D. F., Dowsett, M., Allred, D. C., Hagerty, K. L., Badve, S., Fitzgibbons, P. L., Francis, G., Goldstein, N. S., Hayes, M., Hicks, D. G., Lester, S., Love, R., Mangu, P. B., McShane, L., Miller, K., Osborne, C. K., Paik, S., Perlmutter, J., Rhodes, A., ... Wolff, A. C. (2010). American Society of Clinical Oncology/College of American Pathologists guideline recommendations for immunohistochemical testing of estrogen and progesterone receptors in breast cancer. Archives of pathology \& laboratory medicine, 134(6), 907-922. https://doi.org/10.5858/134.6.907

11. ASCO/CAP guidelines 2018 for HER2 testing: https://www.asco.org/sites/newwww.asco.org/files/content-files/practice-and-guidelines/documents/2018-her2-testing-summarytable.pdf

12. Goldhirsch, A., Winer, E. P., Coates, A. S., Gelber, R. D., Piccart-Gebhart, M., Thürlimann, B., ... \& Wood, W. C. (2013). Personalizing the treatment of women with early breast cancer: highlights of the St Gallen International Expert Consensus on the Primary Therapy of Early Breast Cancer 2013. Annals of oncology, 24(9), 2206-

2223. https://www.sciencedirect.com-/science/article/pii/S0923753419369649

13. Filipits, M., Rudas, M., Singer, C. F., Fitzal, F., Bago-Horvath, Z., Greil, R., ... \& Dubsky, P. (2021). ESR1, PGR, ERBB2, and MKi67 mRNA expression in postmenopausal women with hormone receptorpositive early breast cancer: results from ABCSG Trial 6. ESMO open, 6(4), 100228. https://www.sciencedirect.com/science/article/pii/S2059702921001897

14. Denkert, C., Link, T., Jank, P., Just, M., Hanusch, C., Brasch, F., ... \& Müller, V. (2019, May). Comparison of an automated cartridge-based system for mRNA assessment with central immunohistochemistry in the neoadjuvant GeparX trial. In Journal of Clinical Oncology (Vol. 37, No. 15). 2318 mill road, ste 800 , alexandria, va 22314 usa: amer soc clinical oncology. https://www.researchgate.net/profile/Paul-Jank/publication/333407035

15. Janeva, S., Parris, T. Z., Nasic, S., De Lara, S., Larsson, K., Audisio, R. A., ... \& Kovács, A. (2021). Comparison of breast cancer surrogate subtyping using a closed-system RT-qPCR breast cancer assay and immunohistochemistry on 100 core needle biopsies with matching surgical specimens. BMC cancer, 21(1), 1-10. https://link.springer.com/article/10.1186/s12885-021-08171-2

16. Wasserman, B. E., Carvajal-Hausdorf, D. E., Ho, K., Wong, W., Wu, N., Chu, V. C., ... \& Rimm, D. L. (2017). High concordance of a closed-system, RT-qPCR breast cancer assay for HER2 mRNA, compared to clinically determined immunohistochemistry, fluorescence in situ hybridization, and quantitative immunofluorescence. Laboratory Investigation, 97(12), 1521-

1526. https://www.nature.com/articles/labinvest201793

Page $12 / 13$ 
17. Mugabe, M., Ho, K. E., Ruhangaza, D., Milner, D., Rugwizangoga, B., Chu, V. C., ... \& Brock, J. E. (2021). Use of the Xpert Breast Cancer STRAT4 for Biomarker Evaluation in Tissue Processed in a Developing Country. American Journal of Clinical Pathology. https://www.researchgate.net/profile/Belson-Rugwizangoga/publication/351977318

18. Silver, D. P., Richardson, A. L., Eklund, A. C., Wang, Z. C., Szallasi, Z., Li, Q., ... \& Garber, J. E. (2010). Efficacy of neoadjuvant Cisplatin in triple-negative breast cancer. Journal of clinical oncology, 28(7), 1145. https://www.ncbi.nlm.nih.gov/pmc/articles/PMC2834466/

19. Zhao Y, Dong X, Li R, Ma X, Song J, Li Y and Zhang D (2015):. Evaluation of the pathological response and prognosis following neoadjuvant chemotherapy in molecular subtypes of breast cancer. Onco Targets Ther; 8:1511. https://www.ncbi.nIm.nih.gov/pmc/articles/PMC4480585/

20. Olfatbakhsh, A., Tafazzoli-Harandi, H., Najafi, S., Hashemi, E. A. S., Sari, F., Hesari, P. M., \& Hosseinpour, P. (2018). Factors Impacting Pathologic Complete Response after Neoadjuvant Chemotherapy in Breast Cancer: A Single-Center Study. International Journal of Cancer Management, 11(5). https://sites.kowsarpub.com/ijcm/articles/60098.html 